\title{
Digital Signal Processing for Measurement Systems Theory and Applications
}

\author{
Gabriele D'Antona \\ Dipartimento di Elettrotecnica - Politecnico di Milano \\ Milan, Italy

\begin{abstract}
Alessandro Ferrero
Dipartimento di Elettrotecnica - Politecnico di Milano Milan, Italy
\end{abstract}




\section{CONTENTS}

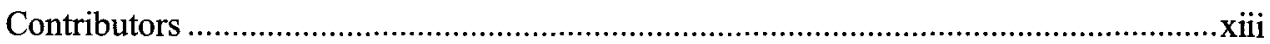

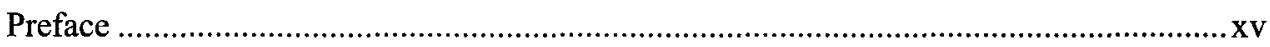

CHAPTER 1 - THE DIGITAL SIGNAL PROCESSING ..............................................

CHAPTER 2 - DISCRETE-TIME SIGNALS AND SYSTEMS ......................................

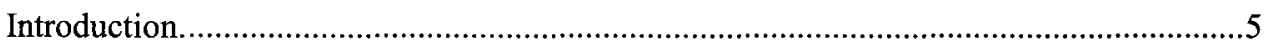

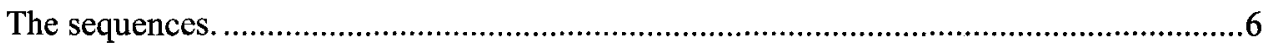

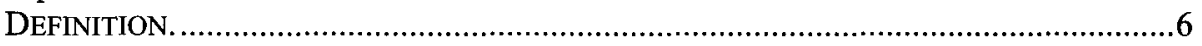

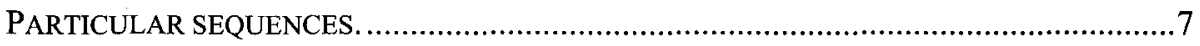

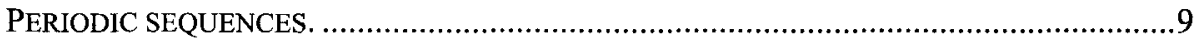

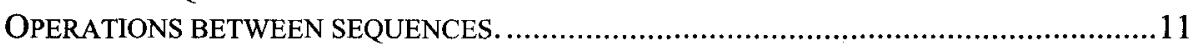

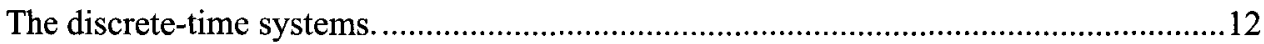

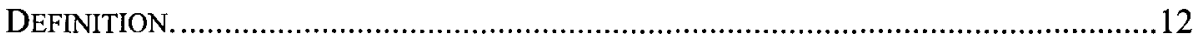

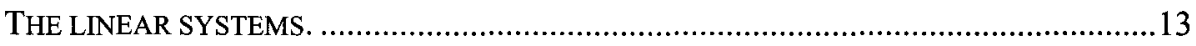

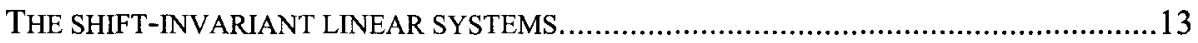

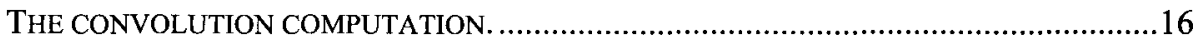

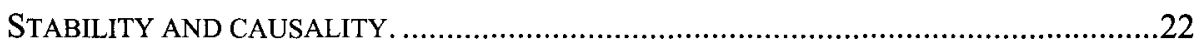


Frequency-domain representation of the discrete-time signals and systems...................24

THE FREQUENCY RESPONSE OF THE LINEAR, SHIFT-INVARIANT SYSTEMS. ................24

THE FOURIER TRANSFORM OF A SEQUENCE. .....................................................29

SYMMETRY PROPERTIES OF THE FOURIER TRANSFORM.........................................31

CHAPTER 3 - SIGNAL TRANSFORMATION FROM THE CONTINUOUS TIME

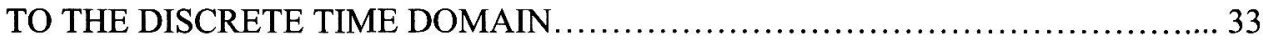

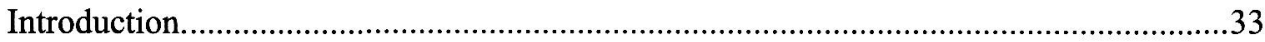

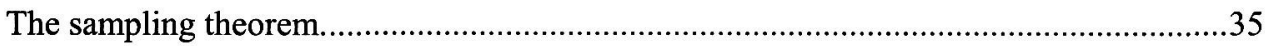

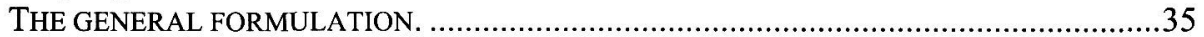

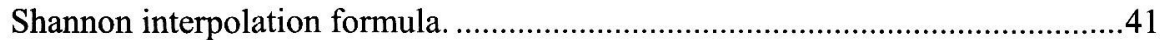

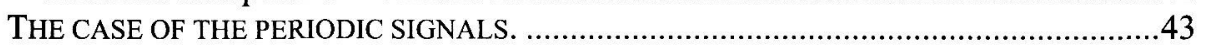

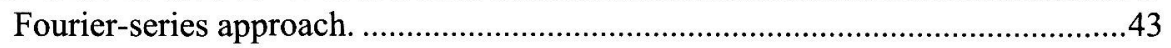

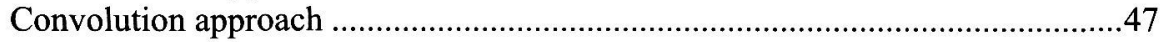

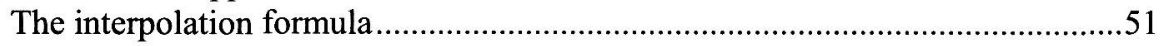

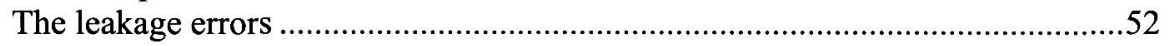

CHAPTER 4 - METHODS FOR THE REDUCTION OF THE LEAKAGE ERRORS..57

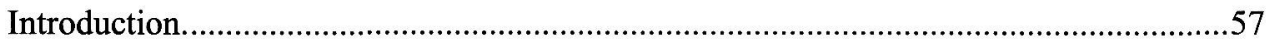

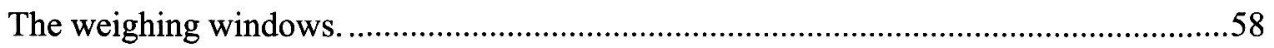

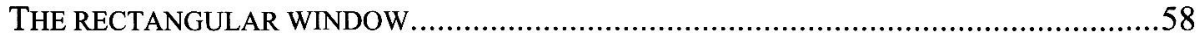

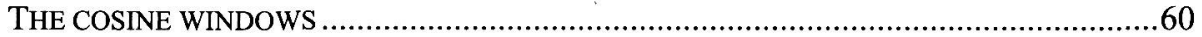

Cosine windows with maximum asymptotic decay .......................................63

Cosine windows with minimum amplitude for the second lobe.........................67

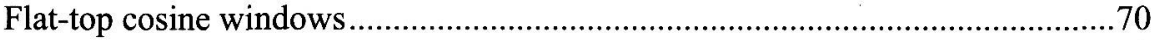

THE SELECTION OF THE OBSERVATION INTERVAL ............................................. 72

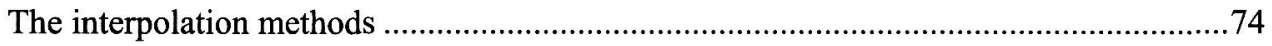

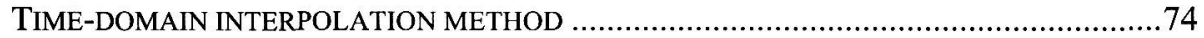

FREQUENCY-DOMAIN INTERPOLATION METHOD ............................................. 76

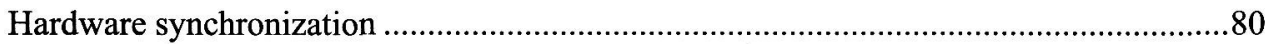

CHAPTER 5 - ARCHITECTURE AND PERFORMANCE OF DSP-BASED

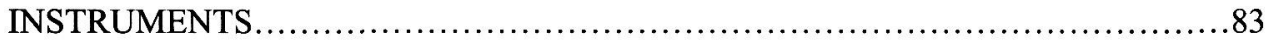

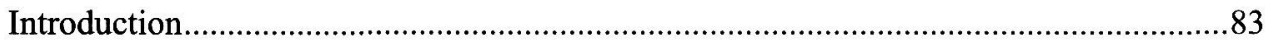

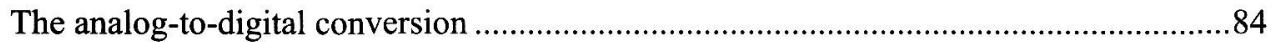

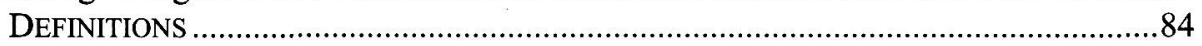




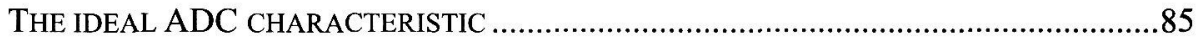

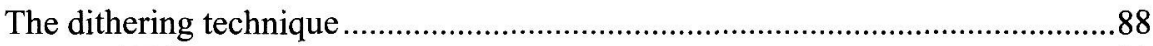

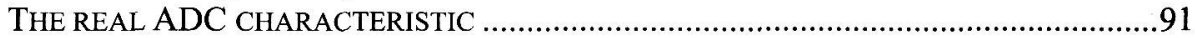

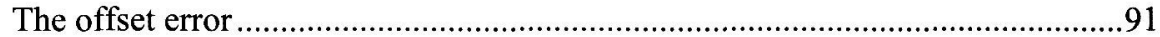

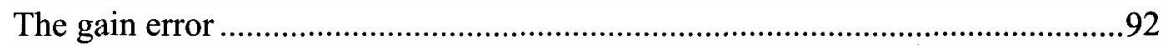

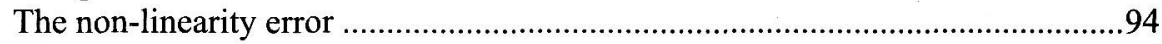

ADC BEHAVIOUR IN THE PRESENCE OF A VARIABLE INPUT SIGNAL ..........................96

The Sample \& Hold devices.............................................................................

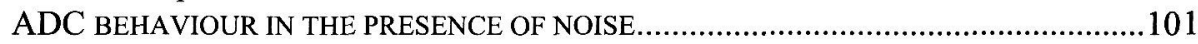

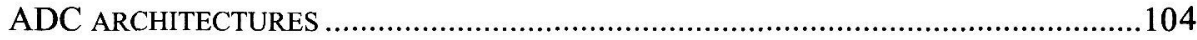

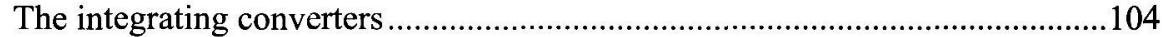

The successive approximation converters ......................................................104

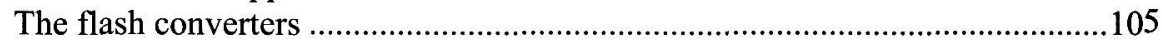

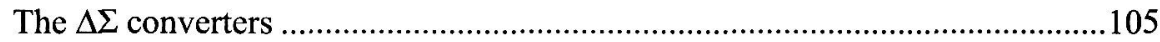

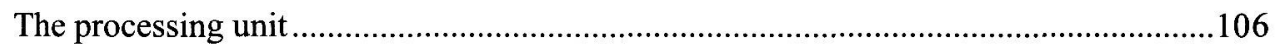

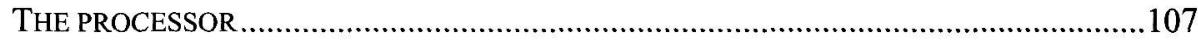

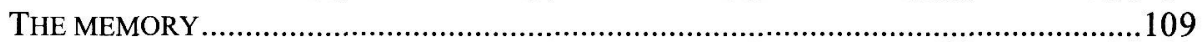

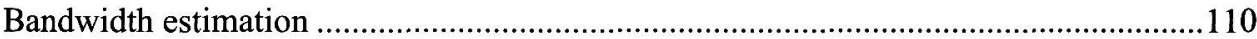

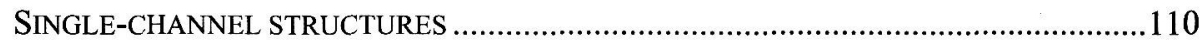

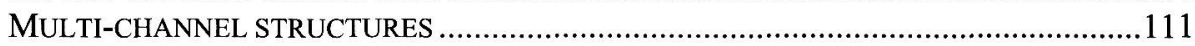

The non-multiplexed structure..................................................................111

The multiplexed structure .............................................................................112

CHAPTER 6 - ANTI-ALIASING METHODS AND SAMPLING STRATEGIES.....115

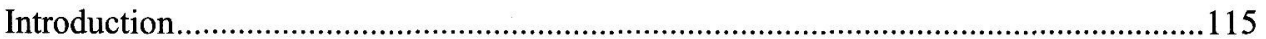

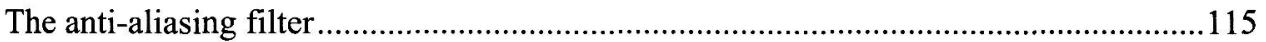

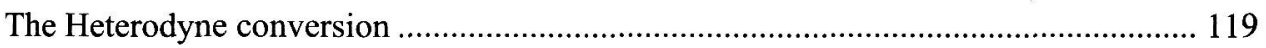

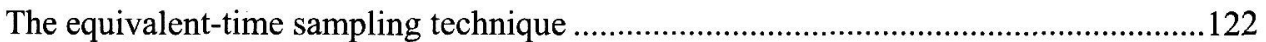

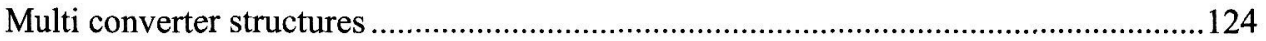


CHAPTER 7 - DYNAMICAL DISCRETE SYSTEMS

Introduction.

Dynamical discrete systems.

$n$-domain representation of dynamical discrete systems: difference equations.

Stability of linear shift invariant discrete systems.

The $z$-transform.

EXAMPLES OF $Z$-TRANSFORMS.

The inverse $z$-transform.

EXAMPLES OF INVERSE $Z$-TRANSFORMS

$z$-domain representation of causal discrete linear shift invariant systems. 162

Linear shift invariant discrete filters.

Relationships between sequences and sampled functions in the $z$ and $s$ domains. 169

CHAPTER 8 - FINITE IMPULSE RESPONSE (FIR) FILTERS

$n$-domain representation of FIR filters.

$z$-domain representation of FIR filters. 180

Linear phase FIR filters 186

FIR filter synthesis by Fourier series expansion.

FIR filter synthesis by the frequency sampling method. 200

Effects of filter coefficients quantization 206

FIR filter architectures. 
$z$-domain representation of IIR filters.

$n$-domain representation of IIR filters.

Purely recursive IIR filters. .224

IIR filters design from analog specifications. .230

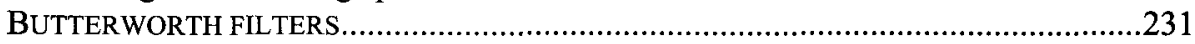

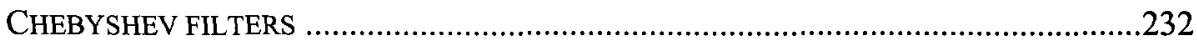

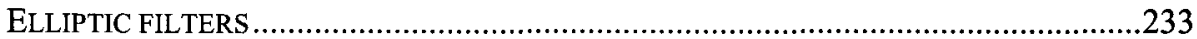

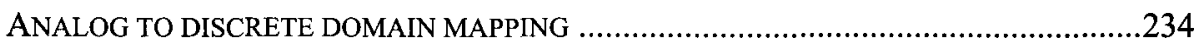

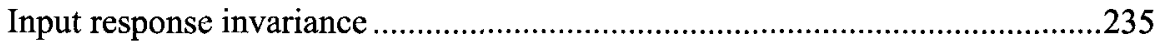

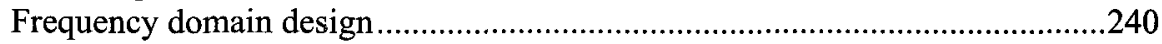

Frequency transformation from low-pass filters to band-pass and

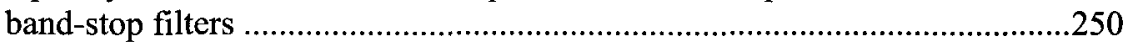

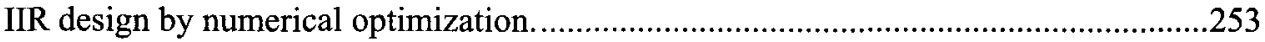

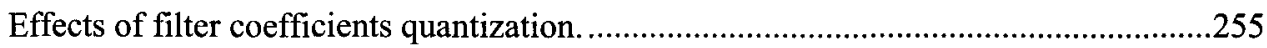

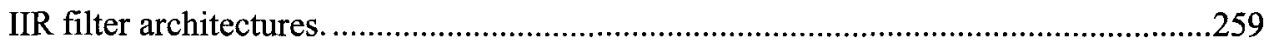

